\title{
Variation of DRB1 Gene in Tibetan Sheep
}

\author{
Li Shaobin, Luo Yuzhu, Hu Jiang, Wang Jiqing, Liu Xiu and Yan Wei \\ Gansu Key Laboratory of Herbivorous Animal Biotechnology, Faculty of Animal Science and Technology, Gansu Agriculture \\ University, Lanzhou 730070, China
}

Received: April 16, 2015 / Accepted: June 7, 2015 / Published: June 30, 2015.

\begin{abstract}
It reveals that the MHC (major histocompatibility complex) gene product always involved in the control of immune response and disease resistance. Nowadays many studies have indicated the OLA (ovine lymphocyte antigen) DRB1 gene is associated with some sheep diseases. Tibetan sheep is one of the three major shag sheep breeds in China, and also have the largest number of China's sheep breeds. But till now no report has been seen on studying DRB1 gene in Tibetan sheep of China. To understand the evolution and provide the basis for sheep disease resistance, polymorphism in the exon2 of DRB1 gene in Tibetan sheep was analyzed. The PCR-SSCP, cloning and sequencing were used to analyse DRB1 gene variation in 600 Tibetan sheep of China. And the genetic relationship and evolutionary significance of the alleles had also been analyzed. Total of 31 alleles were identified, in which 15 alleles had not been reported before. And there were 70 SNPs (single nucleotide polymorphisms) sites in 31 sheep DRB1 gene haplotypes, the proportion was $29.5 \%$ to the whole exon2 sequence. All of this indicated that $D R B 1$ exon2 is highly polymorphic in Tibetan sheep. The variation identified here might have an impact on both the function and level of expression of the OLA-DRB1.
\end{abstract}

Key words: Tibetan sheep, PCR-SSCP, DRB1 gene, polymorphism, genetic variation.

\section{Introduction}

The MHC is a group of genes, which is proved tightly linked and high polymorphic [1,2], and its coding product is known as MHC antigen or MHC molecule. The MHC molecule is related with animal's immunology.

In sheep, MHC is called OLA which located on Chromosome 20. The MHC molecule can be divided into three classes according to the immune nature in mammals: class 1 , molecule is transplantation antigen which responsible for the distinction between "self" and "non-self" organization; class 2, molecule is involved in information transmission between cells in the immune response which mainly distributes in the surface of $\mathrm{B}$ lymphocytes, $\mathrm{T}$ lymphocytes and macrophages; class 3, molecule mainly involved in non-specific immune response. The $D R B 1$ is the most polymorphic part in class 2 molecule, while the exon 2

Corresponding Author: Luo Yuzhu, Ph.D, professor, research field: animal biotechnology. E-mail: luoyz@gsau.edu.cn. of $D R B 1$ gene is the most polymorphic region which encodes the antigen- binding sites. To data, more than 1,000 OLA-DRB1 alleles have been identified, while the number of HLA-DRB1 alleles is over 160 , it suggested that there would be more OLA-DRB1 alleles could be identified [3-5].

To do research on MHC region is very important for it reveals that the MHC gene product always involved in the control of immune response and disease resistance. Nowadays many studies have indicated the OLA-DRB1 gene is associated with some sheep diseases, which often lead to a decrease in production. Buitkamp et al. [6] confirmed that the $D R B$ alleles were strongly associated with faecal egg counts which produced by the parasite Ostertagia circumcincta. Nagaoka et al. [7] determined that OLA-DRB1 alleles associated with resistance or susceptibility to development of ovine lymphoma induced by BLV (bovine leukemnic virus). Jia et al. [8] studied the relationship between OLA-DRB1 alleles and genetic susceptibility to hydatidosis in Chinese 
Merino sheep, the results showed that the allele HaeIII-d was associated with susceptibility and the genotypes of HaeIII-ab and HaeIII-ee were associated with resistance, while the genotype of HaellI-bd was associated with susceptibility to hydatidosis. Herrmann-Hoesing et al. [4] studied the OPP (ovine progressive pneumonia) provirus levels associated with breed and OVAR-DRB1 using 383 ewes of the Columbia, Polypay, and Rambouillet breeds, the results suggested that as one host genetic factor that controlled OPP provirus levels, but did not fully account for the breed-specific OPP proviral differences. But till now no report has been seen on studying DRB1 gene in Tibetan sheep of China. Tibetan sheep is an age-old sheep breeds in China which is one of three major shag sheep breeds in China, distributed at an altitude of 3,500-5,000 $\mathrm{m}$ of the Qinghai-Tibet Highland areas, and also have the largest number of China's sheep breeds. Qinghai-Tibet Plateau is known as Roof of the World where the winter is very cold and the altitude is extremely high. The special climate and geographical made the Tibet breeds have strong resistance to diseases.

Thus, the main purposes of the present study were:

(1) To investigate the polymorphisms of $D R B 1$ gene in Tibetan sheep and determine the DRB1 gene alleles and polymorphic loci use SSCP method, which could provide a research basis for studying the association between MHC and resistance or susceptibility to diseases.

(2) Study the genetic and evolutionary relationships between different alleles to better understand the evolution of species in Tibetan sheep.

\section{Materials and Methods}

This experiment was conducted at the Gansu Key Laboratory of Herbivorous Animal Biotechnology in China from March 2009 to December 2010.

\subsection{Sheep and DNA Sources}

Total 600 Tibetan sheep blood samples from Luqu county of Gansu province of China were collected. And genomic DNA was isolated from blood samples according to the method described in Molecular Cloning [9]. Luqu county is located in the southwest of Gansu Province and eastern edge of Qinghai-Tibet Plateau (101'35'36"-102 $58^{\circ} 15^{\prime \prime}$ $\mathrm{E}$, $\left.33^{\circ} 58^{\prime} 21^{\prime \prime}-34^{\circ} 48^{\prime} 48^{\prime \prime} \mathrm{N}\right)$. The average elevation is $3,500 \mathrm{~m}$, annual average temperature is $2.3^{\circ} \mathrm{C}$, annual precipitation is about $633-782 \mathrm{~mm}$, grass withering period is about $280 \mathrm{~d}$. Disastrous weather is frequent and natural condition is harsh.

\subsection{PCR Amplification}

A $279 \mathrm{bp}$ region covering whole exon 2 and portion of intron1 of $D R B 1$ were amplified by the primes (Takara Biotech. Co. Ltd. China) reported by Ammer et al. [10]. They were $D R B$-up: 5'-TCTCTGCAGCACATTTCCTGG-3' and $D R B$-dn: 5'-CTCGCCGCTGCACAGTGAAAC-3. Each PCR was performed in a $25-\mu \mathrm{L}$ reaction volume containing $50 \mathrm{ng}$ of genomic DNA, $1 \mu \mathrm{L}(10 \mathrm{pmol} / \mu \mathrm{L})$ of each primer, dNTP $(10 \mathrm{mM}) 0.35 \mu \mathrm{L}, 10 \times$ PCR buffer (contain $15 \mathrm{mM} \mathrm{Mg}^{2+}$ ) $2.5 \mu \mathrm{L}$, and $0.75 \mathrm{U}$ of Taq polymerase. And all these medicines' agent company was TianGen Biotech. Co. Ltd. China. The PCR amplification conditions were as follows: preheating at $94{ }^{\circ} \mathrm{C}$ for $5 \mathrm{~min}$, followed by 35 cycles of $94{ }^{\circ} \mathrm{C}$ for $50 \mathrm{~s}, 60{ }^{\circ} \mathrm{C}$ for $30 \mathrm{~s}$ and $72{ }^{\circ} \mathrm{C}$ for $50 \mathrm{~s}$ with final extension at $72{ }^{\circ} \mathrm{C}$ for $10 \mathrm{~min}$. The PCR products were tested by agarose gel electrophoresis.

\subsection{Single-Strand Conformational Polymorphism Analysis}

Mixed $8 \mu \mathrm{L}$ of each amplified product with $2 \mu \mathrm{L}$ of loading dye (98\% formamide, $10 \mathrm{mM}$ EDTA, $0.025 \%$ xylene-cyanol, $0.025 \%$ bromophenol blue). The mixture was denatured at $95{ }^{\circ} \mathrm{C}$ for $10 \mathrm{~min}$, and then immediately chilled on ice and then loaded on $12 \%$ acrylamide:bisacrylamide (39:1; Bio-Rad) gels. Electrophoresis was performed at $220 \mathrm{~V}$ for $20 \mathrm{~h}$ at $16{ }^{\circ} \mathrm{C}$ in $1 \times$ TBE buffer. Gels were silver-stained 
according to the method of Bassam et al. [11].

\subsection{Cloning of PCR Amplimers, Clone Screening and Sequencing}

DNA samples of different SSCP patterns were purified using DNA gel extraction kit. The purified PCR products were ligated to the PGM-T vector (Tiangen biotech, China) according to the manufacturer's instructions. A $3-\mu \mathrm{L}$ aliquot of the ligation mixture was used to transform competent DH5a Escherichia coli cells. Between 8 to 14 insert positive colonies for heterozygous samples were picked while for homozygous samples 3 ones were picked and incubated overnight in LB medium with AMP at $37{ }^{\circ} \mathrm{C}$, in a shaking rotary incubator $(200$ $\mathrm{rpm})$. Then the bacterial liquid was used for PCR amplification and SSCP analysis together with the corresponding PCR product of DNA sample to make sure cloning the right products. And the qualified bacterial liquid was used for sequencing by Beijing Genomics Institute, China.

\subsection{Sequence Analysis}

Sequences were compared with other $D R B 1$ alleles that already identified by other people and published on NCBI database (http://www.ncbi.nlm.nih.gov/). Clustal $\mathrm{X}$ was used for homologous sequence alignment analysis [12]. And Dnasp 4.0 was used for analyse nucleotide variation sites and amino acid mutation [13]. Neighbor-joining tree was constructed on the basis of genetic distance, estimated by Kimura [14] two-parameter method, using MEGA version 4 [15].

\section{Results}

There were 31 SSCP patterns detected. Selected out that could represent all of the band forms, then conducted clone and the bacterial liquid was used for PCR amplification and SSCP analysis together with the corresponding genomic DNA sample to make sure cloning the right products. SSCP patterns were sequenced. After comparison analyses of sequences, there were 31 different sequences identified. This means that 31 alleles were detected, and named "B1" to "B31". And the nucleotide sequences alignment of these 31 alleles was conducted (Table 1). Exclude primer, target fragment was $237 \mathrm{bp}$. The results of sequence comparisons showed that there were total of 70 SNPs' sites, which is $29.5 \%$ of total sequence. In which, there are 28 transition mutation sites, composed $40 \%$ of total variable sites; 16 transversion mutation sites composed $37.1 \%$, respectively; 15 variable sites both have transition mutation and transversion mutation. The results of sequence comparison with NCBI date base showed that B1 to B16 had the same sequences with sequences that already been reported on NCBI, the GenBank accession number respectively were: DQ659116.2, FM998807.1, DQ659119.2, Z92734.1, AY884015.2, AY884011.2, $\quad$ FM209041.1, $\quad$ DQ659124.2, AB061318.1, DQ659127.2, DQ659122.2, Z92733.1, Z92732.1, FN543113, FM209549.1, DQ659131.2. And from B17 to B31 these 15 patterns were confirmed as novel variation in OLA-DRB1. Then the DNA sequences were deposited into GenBank with accession nos. JF898304-JF898318.

To study the genetic and evolutionary relationships between different alleles, two neighbor-joining phylogenetic trees were built using MEGA 4 (Fig. 1). According to Bootstrap Values, this cluster figure could divide into two main branches. The I branch included $26 D R B 1$ alleles and the II branch included $5 D R B 1$ alleles.

\section{Discussion}

Extensive genetic diversity in MHC genes provides valuable sources for genetic improvement, via selection [16]. DRB1 gene is the most polymorphic part of MHC family, at the same time the exon2 of it encodes the antigen-binding sites, so for the DRBI gene polymorphisms and disease correlation studies very hot. Jia et al. [8] studied $D R B 1$ gene polymorphism 
Table 1 Nucleotide sequences alignment of $D R B 1$ gene exon2 alleles.

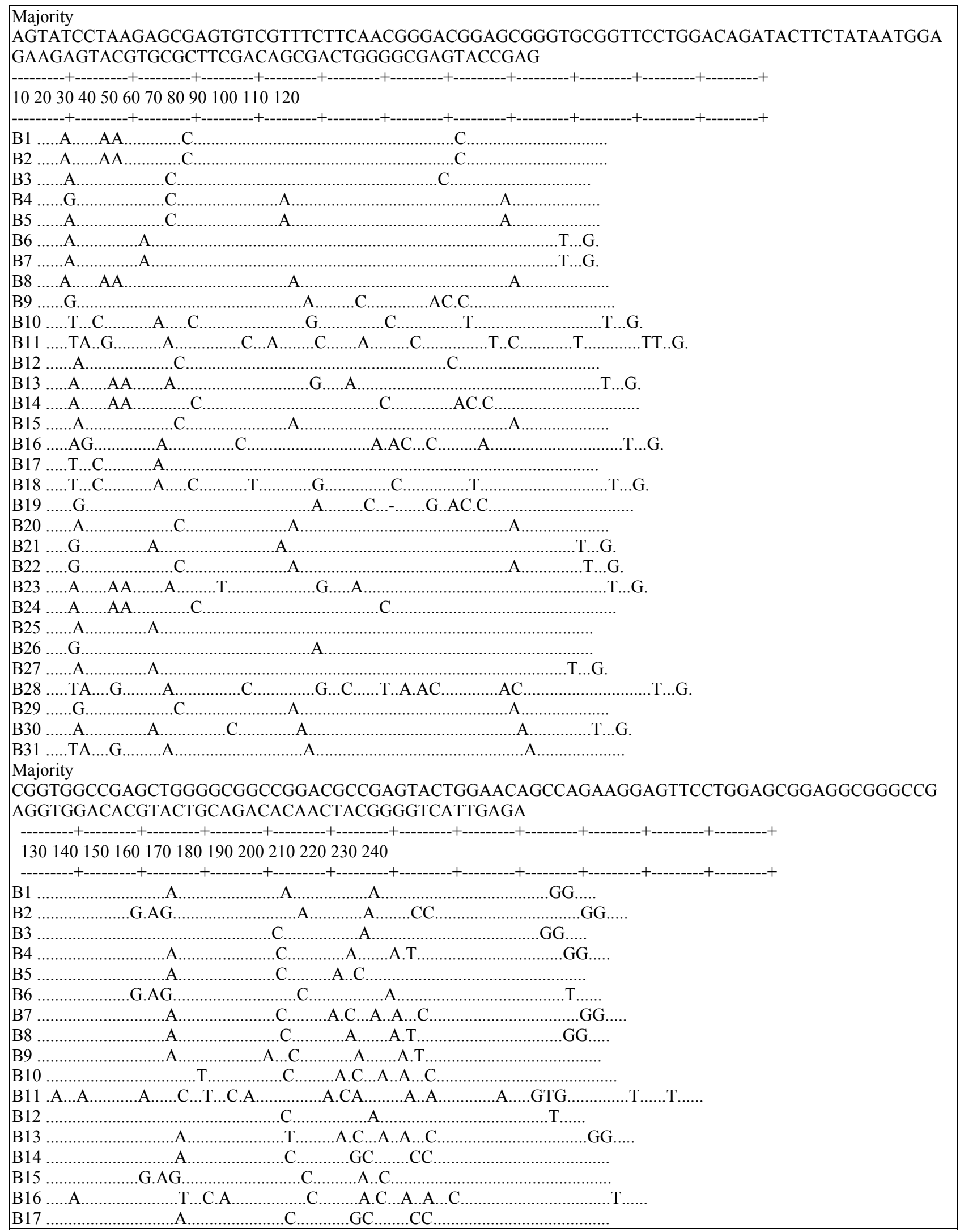


Table 1 to be continued

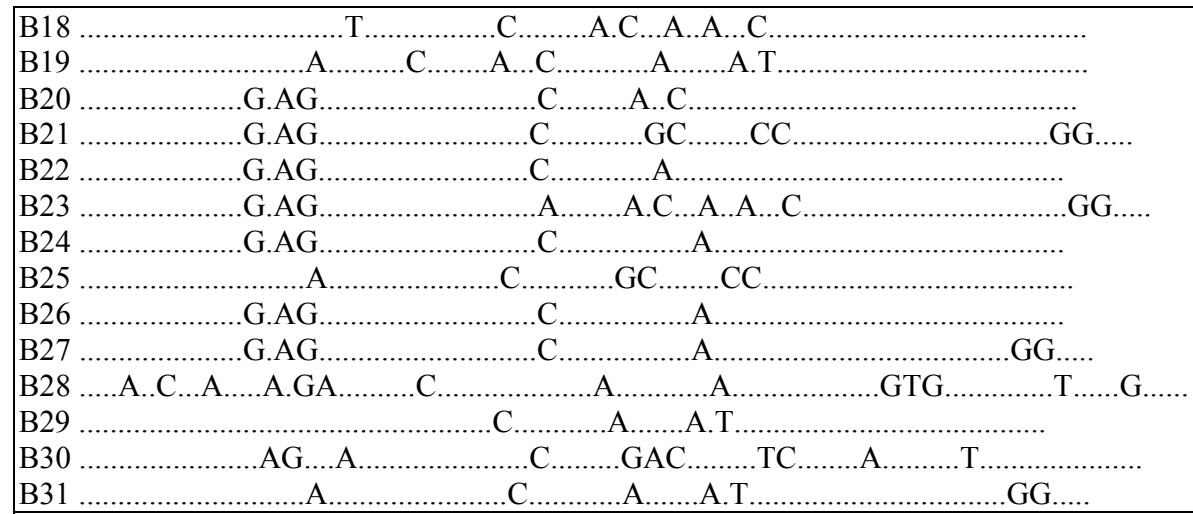

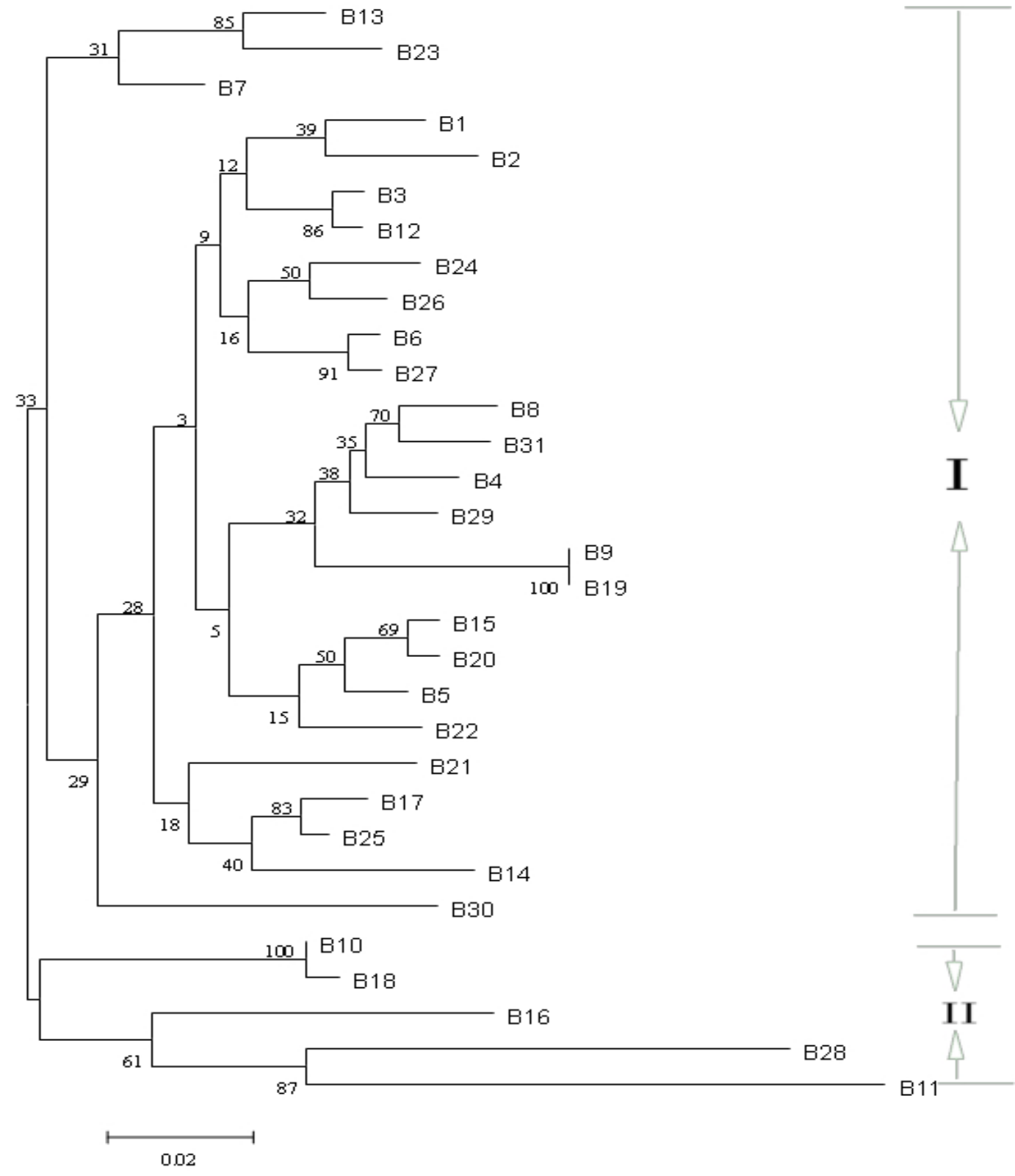

Fig. 1 Neighbor-joining phylogenetic tree of OLA-DRB1. 
of 192 Duolang sheep (a Chinese local sheep) and 199 Chinese Merino sheep using PCR-RFLP method, and detected 10 alleles. Jugo and Vicario [17] studied DRB1 gene polymorphism of exon2 of 83 Latxa and Karrantar sheep using PCR-SSCP method, and detected 12 DRB1 alleles. Konnai et al. [18] studied $D R B 1$ gene polymorphism of exon2 of 71 Suffolk sheep by sequencing analysis, and found 28 DRB1 alleles. Tkacikova et al. [19] studied DRB1 gene polymorphism of 400 Valachian sheep and detected 25 DRB1 alleles. The results of other studies about OLA-DRB1, Kostia et al. [20] studied on Finnish and Russian sheep breeds, Ballingall et al. [21] studied on Blue-faced Leicester rams Blackface sheep, Stirling et al. [22] studied on Scottish Blackface rams, which were all proofed $D R B 1$ gene is highly polymorphic. In the present study, polymorphisms of the second exon of DRB1 gene in 600 Tibetan sheep were firstly conducted using PCR-SSCP method and detected 31 $D R B 1$ alleles. These studies on DRB1 had same results with the study which indicated $D R B 1$ was a high level polymorphic gene. The extreme high level of polymorphism of MHC loci may be a result of the evolutionary consequences of intensive interactions between infections pathogens and the host defensive system [23]. This polymorphisms may be consistent with Tibet sheep characterized strong adaptability and disease resistance who lived in high-altitude and harsh ecological environment. Tibet sheep distributed in 3,500-5,000 $\mathrm{m}$ high altitude areas of China and the breeding stock is around 34 million. This breed is the main body of Qinghai-Tibet Plateau sheep industry and also an important component of China's sheep industry, part of the main superior resources in pastoral areas [24]. In the Qinghai-Tibet Plateau's unique geographical environment and climatic conditions, and in the long-term evolution and adaptation progress, the Tibet sheep formed a rich genetic diversity which is confirmed by the 15 new $D R B 1$ alleles of the study. At the same time the new $D R B 1$ alleles have also enriched gene pool.
Neighbor-joining phylogenetic tree of OLA-DRB1 gene showed that in the evolutionary process of Tibet sheep OLA-DRB 1 gene was originally proposed by two mutant alleles to differentiate into two major categories of alleles. Tibetan sheep genetic resources were comprehensive and representative that provided a theoretical basis for the Tibetan sheep MHC specific haplotypes breeding. This is only a preliminary study on the polymorphism of the OLA-DRB 1 gene in Tibetan sheep to provide a basis for further work. However whether these variations detected in the ovine exon 2 of the DRB1 gene is functional or not is still unclear, we need to enlarge sample size to verify these results and further analyze the association between the OLA-DRB1 gene and disease resistance.

\section{Conclusion}

OLA-DRB1 gene of Tibetan sheep showed high level of polymorphism that provides valuable information on comparative genome evolution in mammals. The amount of sequence information available for sheep is still limited by compare of HLA-DRB 1, and there are lots of works need to do.

\section{Acknowledgments}

Project supported by the Funds of National Key Technology R\&D Program of China (Grant No. 2012BAD13B05-02), International Cooperation Projects (Grant No. 2011DFG33310), Creative Research Groups of Gansu Province (Grant No. 1210RJIA005) and International Cooperation Projects of Gansu Province (Grant No. 1304WCGA178).

\section{Reference}

[1] Tizard, I. R. 2004. "Acquired Immunity: Antigen-Presenting Receptors." In Veterinary Immunology: An Introduction, edited by Tizard, I. R. 7th Edn., Philadelphia: Elsevier.

[2] Dukkipati, V. S. R., Blair, H. T., Garrick, D. J., and Murray, A. 2006. "Ovar-Mhc-Ovine Major Histocompatibility Complex: Role in Genetic Resistance to Diseases." Genet. Mol. Res. 5 (4): 581-608. 
[3] Konnai, S., Nagaoka, Y., Takeshima, S., Onuma, M., and Aida, Y. 2003a. "Sequences and Diversity of $17 \mathrm{New}$ Ovar-DRB1 Alleles from Three Breeds of Sheep." Eur. J. Immunogenet 30: 275-82.

[4] Herrmann-Hoesing, L. M., White, S. N., Mousel, M. R., Lewis, G. S., and Knowles, D. P. 2008. "Ovine Progressive Pneumonia Provirus Levels Associate with Breed and Ovar-DRB1.” Immunogenetics 60: 749-58.

[5] Robinson, J., Mistry, K., McWilliam, H., Lopez, R., Parham, P., and Marsh, S. G. E. 2011. "The IMGT/HLA Database." Nucleic Acids Research 39 Suppl 1: D1171-6.

[6] Buitkamp, J., Filmether, P., and Stear, M. J. 1996. "Class I and Class II Major Histocompatibility Complex Alleles Are Associated with Faecal Egg Counts Following Natural, Predominantly Ostertagia Circumcincta Infection.” Parasitol. Res. 82 (8): 693-6.

[7] Nagaoka, Y., Kabeya, H., Onuma, M., Kasai, N., Okada, K., and Aida, Y. 1999. "Ovine MHC Class II DRB1 Alleles Associated with Resistance or Susceptibility to Development of Bovine Leukemia Virus-Induced Ovine Lymphoma1." Cancer Res. 59: 975-81.

[8] Jia, B., Shen, H., Yu, Z. Y., Chen, M. H., and Liu, H. K. 2007. "Polymorphism of the Ovine Major Histocompatibility Complex Class II DRB1 Gene and the Genetic Susceptibility to Hydatidosis." Chin. J. Zoonoses. 23: 1004-8.

[9] Sambrook, J., Frotsch, E. F., and Maniatis, T. 1989. Molecular Cloning: A Laboratory Manual. 2nd Edn., New York: Cold Spring Harbor Laboratory Press.

[10] Ammer, H., Schwaiger, F. W., Kammerbauer, C., Gomolka, M., Arriens, A., Lazary, S., and Epplen, J. T. 1992. "Exonic Polymorphism VS Intronic Simple Repeat Hypervariability in MHC-DRB Genes." Immunogenetics 35: 332-40.

[11] Bassam, B. J., Caetanoanolles, G., and Gresshoff, P. M. 1991. "Fast and Sensitive Silver Staining of DNA in Polyacrylamide Gels." Anal. Biochem 196: 80-3.

[12] Thompson, J. D., Gibson, T. J., Plewniak, F., Jeanmougi, F., and Higgins, D. G. 1997. "The CLUSTAL_X Windows Interface: Flexible Strategies for Multiple Sequence Alignment Aided by Quality Analysis Tools." Nucleic. Acids. Res. 25: 4876-82.

[13] Rozas, J., Sanchez-DelBarrio, J. C., Messeguer, X., and Rozas, R. 2003. "DnaSP, DNA Polymorphism Analyses by the Coalescent and Other Methods." Bioinformatics 19: 2496-7.
[14] Kimura, M. 1980. "A Simple Method for Estimating Evolutionary Rate of Base Substitution through Comparative Studies of Nucleotide Sequences." J. Mol. Evol. 16: 111-20.

[15] Kumar, S., Tamura, K., and Nei, M. 2004. "MEGA3: Integrated Software for Molecular Evolutionary Genetics Analysis and Sequence Alignment." Bioinformatics 5: 150-63.

[16] Jamshidi, R., Nikbakht Brujeni, G. H., Derakhshandeh, A., and Talebnia, R. 2011. "Exon2 Ovar-DRB1 Gene Polymorphismin the Iranian Sangsari Sheep." Int. J. Vet. Res. 1: 59-62.

[17] Jugo, B. M., and Vicario, A. 2000. "Single-Stand Conformational Polymorphism and Sequence Polymorphism of Mhc-DRB in Latxa and Karrantzar Sheep: Implication for Caprinae Phylogeny." Immunogenetics 51: 887-97.

[18] Konnai, S., Nagaoka, Y., Takesima, S., Onuma, M., and Aida, Y. 2003b. "Technical Note: DNA Typing for Ovine MHC DRB1 Using Polymerase Chain Reaction-Restriction Fragment Length Polymorphism (PCR-RFLP).” J. Dairy Sci. 86: 3362-5.

[19] Tkacikova, 1., Bhide, M. R., and Mikula, I. 2005. "Asymmetric PCR-SSCP: A Useful Tool for Detection of OLA-DRB1 (MHC Class II) Gene Polymorphism in Slovak Improved Valachian Sheep." ACTA VET. BRNO. 74: $275-8$

[20] Kostia, S., Kantanen, J., Kolkkala, M., and Varvio, S. L. 1998. "Applicability of SSCP Analysis for MHC Genotyping: Fingerprinting of Ovar-DRB1 Exon2 Alleles from Finnish and Russian Breeds." Anim Genet. 29: 453-5.

[21] Ballingall, K. T., Fardoe, K., and McKeever, D. J. 2008. "Genomic Organisation and Allelic Diversity within Coding and Non-coding Regions of the Ovar-DRB1 Locus." Immunogenetics 60: 95-103.

[22] Stirling D., and Stear, M. J. 2010. "The Direct Determination of Haplotypes from Extended Regions of Genomic DNA.” BMC Genomics 11: 223.

[23] The MHC Sequencing Consortium. 1999. "Complete Sequence and Gene Map of a Human Major Histocompatibility Complex." Nature 401: 921-3.

[24] Yang, J. T., Zhang, R. X., Liu, W. J., Xu, H. W., Bai, J. L., Lu, J. X., and Wu, J. P. 2011. "Polymorphism of a Mutation of DGAT1 Gene in Four Chinese Indigenous Sheep Breeds." Asian J. Anim. Vet. Adv. 6 (5): 460-8. 